\title{
La Caracterització dels personatges femenins en Helena d'Eurípides a través del text i del seu context
}

\section{Characteristics of female characters in Euripides' Helen through the text and its context}

\author{
DOI: $10.46932 /$ sfjdv2n5-105
}

Received in: Oct 1st, 2021

Accepted in: Dec 30th, 2021

\author{
Aïda Mifsut Ferrús \\ Graduada en Filología clásica por la Universidad de Valencia. \\ Máster Universitario en Profesora de Educación Secundaria por la Universidad de Valencia. \\ Institución: Instituto de Educación Secundaria Obligatoria \\ Camí la Dula, 31, 46760 Tavernes de la Valldigna, Valencia \\ E-mail: aidamifsut@gmail.com
}

\section{RESUMEN}

La figura de Helena ha influido sobre manera en la línea interpretativa de la obra homónima. Son numerosos los estudios críticos que señalan el cambio radical que experimenta Helena en el transcurso de la obra. Quienes opinan que constituye una incoherencia inaceptable el contraste entre una Helena doliente y pasiva en la primera mitad de la obra y una Helena activa y urdidora de un plan de huida en la segunda, orientan su estudio de la caracterización a determinar el tipo de persona encarnado por Helena, es decir, en el tipo de persona que ella es, y de ahí que señalen negativamente esa discordancia en su caracterización. Sin embargo, este cambio en el personaje principal no es el foco de todos los problemas de interpretación de esta tragedia euripídea: la crítica moderna ha etiquetado de modo diverso, en primer lugar, la inclusión de elementos cómicos dentro de una pieza dramática. En segundo lugar, la conexión o no de la pieza con el clima político y militar de la época y, como consecuencia, su consideración de tragedia pacifista. En tercer lugar el papel esencial del elemento divino en una tragedia que aparenta la crisis o ruptura con él. Por último, la valoración del sustrato filosófico sobre el que Eurípides ha construido la obra. En este trabajo intentaremos arrojar cierta luz sobre estas cuatro cuestiones, sin perder de vista la relación de género establecida por la heroína y por un personaje central a la par que complejo dentro de esta tragedia: el coro. De gran repercusión es la crítica vertida hacia la lírica de este grupo de mujeres griegas cautivas en una tierra extranjera y queremos con nuestro trabajo destacar la centralidad del coro como personaje en la acción dramática, que, junto con Helena, sufre un progresivo desarrollo en su identidad y hace de esta obra una obra maestra del autor.

Palabras clave: Teatro griego, tragedia, Eurípides, Helena.

\begin{abstract}
The character of Helen has extremely influenced the interpretative line of the homonymous tragedy. There are numerous critical studies that point to the radical change that Helen experiences during the course of the play. Those who think that the contrast between a woeful and passive Helen in the first half of the play and an active Helen who plots a escape plan in the second half is an unacceptable incoherence, based their study on the type of person incarnated by Helen, that is, on the type of person she is, and hence they point negatively to that discordance in her characterization. However, this change in the main character is not the focus of all the interpretation problems of this Euripidean tragedy: in the first place, modern criticism has labeled in different ways the inclusion of comic elements within a dramatic piece; second, the connection of the play with the political and military context of the period and, as a consequence, its
\end{abstract}


consideration of a pacifist tragedy; third, the essential role of the divine element in a tragedy that seems in crisis or rupture with it, and finally, the assessment of the philosophical substrate on which Euripides has composed his drama. In this work we will try to shed some light on these four issues, without losing sight of the gender relationship established by the heroine and by a central and complex character within this tragedy: the chorus. Of great importance is the criticism towards the poetry of this group of Greek captive women in a foreign land and with our work we want to highlight the centrality of the chorus as a character in the dramatic action, which, together with Helen, undergoes a progressive development in its identity and makes this tragedy a masterpiece of the author.

Keywords: Greek drama, tragedy, Euripides, Helen.

\section{L'ORIGEN DEL TEATRE I LA TRAGÈDIA}

El teatre grec va nàixer a l'Àtica al segle VI aC i es representava en festes de caràcter cívic i religiós. Anava dirigit a un públic molt ample, tenia la funció d'educar una col·lectivitat i els dramaturgs

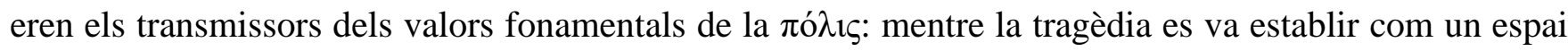
de presa de consciència i de reflexió dels problemes estructurals i superestructurals, la comèdia ho va fer com a vàlvula d'escapament de la pressió social present en tota la comunitat.

El drama antic va constituir una síntesi cultural única d'elements, on el context de les representacions estava marcat per la democràcia atenenca del s. V aC i per tant el seu recipient, el ciutadà espectador de la $\pi$ ó $\lambda ı \varsigma$, experimentava i interpretava l'espectacle en escena baix un transfons relativament homogeni. Ja que la paraula parlada de la tragèdia i la comèdia oferia els interessos i el món real de l'espectador, la seua actitud i expectació pel que fa a la seua obra era el que més preocupava al dramaturg. Així doncs, donat un material mític conegut, no era important l'objectivitat de la narració, sinó les conseqüències que l'acció en escena tenia en la consciència dels espectadors que participaven en l'espectacle.

El drama estava connectat amb l'esfera pública i religiosa de la ciutat i els missatges que el públic rebia tenien un valor formatiu i educatiu tant per a cada individu en particular com també per a la $\pi$ ó $\lambda 1 \varsigma$ com un tot. Eixe valor col·lectiu també tenia un rol social al constituir-se una nova consciència del ciutadà atenenc com a espectador amb experiències culturals, metes i interessos similars dins de la formació de la ciutat-estat.

Els ciutadans s'agrupaven en un ambient de cohesió total i absoluta en què els elements religiosos, polítics i socials estaven entrellaçats. La tragèdia no queda fora d'aquest ordre, doncs les representacions eren organitzades i subvencionades per l'Estat, per la qual cosa adquirien una dimensió col·lectiva i estatal. L'interés de 1'Estat no era promoure les representacions com una mera funció literària o de divertiment, sinó que buscava suscitar l'interés del públic, plasmant la problemàtica social del moment. Així, el teatre no pretenia plasmar la realitat en què se circumscrivia l'obra, sinó qüestionar aquesta 
realitat. Al mateix temps que es representaven històries dels orígens heroics, passat històric i remot del poble grec, es tractaven els temes d'actualitat relacionats amb la $\pi$ ó $1 \varsigma$ atenenca. ${ }^{1}$

A través del mite es conforma una de les característiques de la tragèdia, que és la relació d'aquesta amb l'espectador i el propi temps. El propi autor en diverses ocasions se n'ix del marc de la representació del mite i es dirigeix als espectadors per a comunicar-los les seues reflexions o advertències. ${ }^{2}$ Un clar exemple el trobem en la producció d'Eurípides, l'obra del qual ens disposem a tractar, en què els esdeveniments presents i la seua rellevància en la civilització grega tenen el seu eco en la representació de les seues tragèdies.

El teatre posseïa influència de dos gèneres anteriors, de l'èpica va prendre els temes $\mathrm{i}$ els personatges, i de la lírica va adquirir la música i la dansa. Sobre l'origen de la tragèdia existeix una controvèrsia, malgrat tots els estudis realitzats pels filòlegs moderns, no es pot parlar amb seguretat sobre l'origen exacte d'aquesta. Ja en l'antiguitat, Aristòtil (Poètica 1449a) va dur a terme un intent per establir i explicar l'origen d'aquest gènere, proposant que fora el ditirambe cantat per un cor de sàtirs front a un solista. La majoria d'estudiosos -consideren que la tragèdia àtica va començar amb l'obra de Tespis, quan, en les festivitats de Dionís, va presentar el seu cor de $\tau \rho \alpha \gamma \omega \delta$ oí representant el que seria el germen de l'obra dramàtica. La novetat de Tespis pareix haver sigut la de traure a un personatge del cor encarregat de recitar uns versos de caràcter més narratiu i informatiu.

Les grans figures mítiques es proposen com a exemple per a l'espectador, amb la intenció de mostrar les conseqüències de l'excessiva supèrbia, les conseqüències de sobrepassar els límits humans. En la tragèdia queda plasmada la visió del món, els anhels, els desitjos de l'home grec, etc.

El teatre grec era realista, els personatges tenien la doble particularitat de ser herois i persones $\mathrm{i}$ aquesta singularitat va acréixer a partir d'Eurípides i Menandre perquè va entrar en eixe moment la sofistica i la profunditat dels personatges es va fer major. Quant al metre, el discurs del teatre es feia principalment en trímetres iàmbics o en tetràmetres trocaics: encara que cada autor utilitzava més uns metres en particular i les parts corals eren exemple de la diversitat i riquesa de la mètrica lírica, aquests dos eren els més habituals. ${ }^{3}$

\footnotetext{
${ }^{1}$ Cf. Vernant-NAquet (1987: 16 i 27), BlÁZquez ET Ali (1989: 692), Di BenEdetto (1997: $315-316$ i 322 ).

${ }^{2}$ Cf. LeSKY (2001: 38), i VernANT-NAQuet (1987: 18 i 26).

${ }^{3}$ Per a una recopilació dels estudis fonamentals de la mètrica en el gènere tràgic, Cf. BUIJS (1985: 62-92).
} 
El teatre va començar a tenir lloc principalment en una festa nacional amb caràcter religiós anomenada les Grans Dionísies, que se celebrava el mes d'E $\lambda \alpha \varphi \eta \beta 0 \lambda \imath \omega^{\prime} .{ }^{4} E n$ aquesta s'honrava a Dionís i estava organitzada per l'arcont epònim ${ }^{5}$ i finançada pel $\chi 0 \rho \eta \gamma o ́ s .{ }^{6}$

Quant als espectadors del teatre, aquests seien agrupats per tribus, exceptuant aquells que tenien dret a $\pi \rho \circ \varepsilon \delta \rho i ́ \alpha,{ }^{7}$ que ho feien sempre a les primeres files. El públic en un primer moment era partícip de l'espectacle, com per exemple sent components del cor, però paulatinament amb la professionalització del teatre, es va produir un cert distanciament i els ciutadans passaren a ser mers espectadors. De la mateixa manera, el teatre també va deixar de tenir lloc sols en les festivitats de caràcter religiós ${ }^{8}$ i va passar a celebrar-se en altres ocasions i contextos socials. L'espectador d'època clàssica es diferencia en gran mesura amb el modern. Actualment s'acudeix al teatre per qüestions psicològiques, sociològiques, antropològiques, històriques, etc, no pel context d'una festa nacional i religiosa. A diferència del món clàssic, avui en dia l'espectador pot haver llegit l'obra abans de veure la representació, pot adquirir coneixements prèviament sobre el gènere i l'autor. En l'antiguitat, els espectadors coneixien els mites, però el que esperaven amb interès era veure en quina mesura l'autor els utilitzaria i els variaria (sempre dins de certes normes que no podien transgredir).

El teatre grec era una qüestió d'Estat. Disposava d'uns mites o textos mitjanament fixes. Açò no vol dir que s'excloïa tota innovació, però sí que era més institucional: la possible innovació era acceptada per la institució que tenia el poder de fer-ho. No hem de pensar que es dóna la mateixa situació en un sistema dictatorial modern amb una censura fèrria, entre altres coses perquè en una societat així sempre hi havia possibilitat d'una representació clandestina. En el teatre atenenc clàssic no és tampoc una qüestió de censura, sinó simplement del fet que el teatre es defineix institucionalment, és una institució de l'Estat. Per tant, hi ha una selecció prèvia i podien caure multes, com li caigueren dos vegades a Aristòfanes. Finalment, durant el segle IV i arran de la dissolució de la idea de $\pi$ ó $\lambda$ ıs, la tragèdia perdrà força, a diferència de la comèdia, que continuarà viva, encara que canviant de forma.

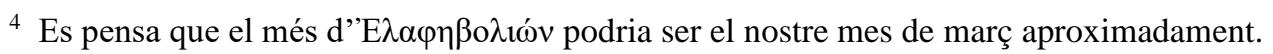

${ }^{5}$ Cf. RIU (2007: 133): "Qui organitzava el conjunt dels rituals era l'anomenat arcont epònim, un dels principals magistrats de l'Estat, que donava nom a l'any en què exercia el càrrec."

${ }^{6}$ Cf. RIU (2007: 133): “corega (khoregos), una mena de productor: el triava l'Estat entre els ciutadans més rics, i l'obligació d'acceptar era quasi total: només hi havia una manera de defugir-ho, força curiosa: el designat podia dir que un altre era més indicat que ell [...]; si l'altre acceptava, tot anava bé; si no, llavors s'anava a un procés d'intercanvi de propietats (antidosis) durant un any."

${ }^{7}$ Dret a seure en la primera fila.

${ }^{8}$ El terme religiós utilitzat no és el que coneixem actualment, sinó el del món clàssic, que estava estretament relacionat amb la moral, l'ètica i la política (assumptes relacionats amb la $\pi$ ó $\lambda ı \varsigma$ ), es trobava dins de la moral de l'estat, com un tot. Es tractava d'una societat primitiva, en què aquests aspectes estaven units, per la qual cosa trobem elements que nosaltres qualificaríem de religiosos en moments de la vida comunitària barrejats amb altres elements que nosaltres mantindríem separats. L'assistència a les representacions (en les quals les dones, cap pensar, estarien excloses) era la clau per a la participació en la $\pi$ ó $ı \varsigma$, reunint tots els ciutadans i unint tots els plans ja mencionats.
} 
En un inici, el director, l'autor i l'actor eren la mateixa persona, però ja en època clàssica comença a separar-se l'actor del director, l'actor passà a ser professional. ${ }^{9}$ Els actors eren tres, un d'ells era l'actor

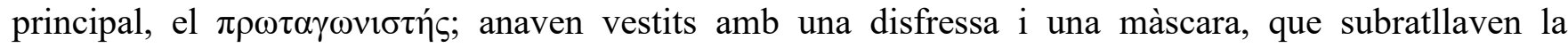
solemnitat que caracteritzava la tragèdia. La màscara de vegades els condicionava la dicció, però permetia

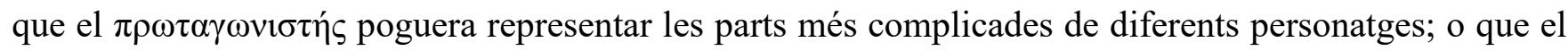

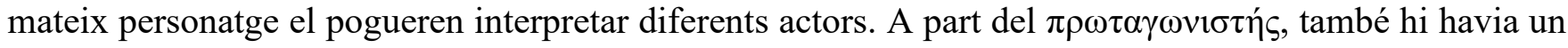
altre professional, el corifeu, que era el cap del cor. A partir del segle IV aC, el teatre s'expandeix i l'actor adquireix una gran consideració social fins el punt que en algunes ciutats estaven exempts de pagar impostos. A part de les Grans Dionísies, també es va introduir el teatre en una altra festa anomenada les Lenees, que se celebrava el mes de $\gamma \alpha \mu \eta \lambda \iota \omega^{10} v^{10}$ era un festival de la comèdia dedicat al Dionís de tot l'àmbit jònic.

El teatre va aconseguir la seua plenitud en poc de temps; va sofrir un procés de professionalització que va anar acompanyat de la formació de diverses companyies itinerants i de la teorització del teatre. El procés de professionalització va anar de forma paral·lela a una teorització del teatre que es considera que va iniciar Aristòtil, qui, com explica LANZA (2002: 77-88), va dur a terme amb el drama la mateixa operació que amb la resta de disciplines que estudia: les delimita i les situa com a disciplines diferents. Quan en Política s'ocupa particularment de l'educació dels ciutadans, una qüestió essencial, com ho veu ell, és establir que tant la poesia com la música tinguen en aquesta un paper destacat. No obstant això, distingeix entre una utilització educativa (política) i una professional: un ciutadà ha d'aprendre aquestes coses fins un cert punt, no ser un virtuós (sí per als professionals, contractats per a "fer passar una bona estona"). D'aquesta manera, salva Aristòtil l'expulsió de la poesia que Plató havia ressaltat en la seua filosofia. Tot i donar-li un paper en la ciutat, va iniciar un procés de traure la poesia del seu lloc central que ocupava en la $\pi$ ó $\lambda ı \varsigma$ per a deixar-la relegada a un lloc més marginal, per a tractar-se amb el temps fonamentalment d'una ferramenta d'oci.

Dins del teatre trobem tres grans gèneres: la tragèdia, la comèdia, i el drama satíric, però nosaltres ens centrarem solament en la tragèdia, perquè l'objectiu d'aquest treball es estudiar principalment l'obra Helena del tragediògraf Eurípides. La tragèdia, segons Aristòtil, és la sublimitat de l'acció perquè narra fets d'un passat mític amb els quals l'espectador no es podia comparar. També considerava que era una

\footnotetext{
${ }^{9}$ Sabem que al s. V no hi havia cap tipus de companyia ni estable ni no estable i no eren professionals, a excepció dels actors. El cor estava constituït per ciutadans i en tot cas formar part d'aquest no era una manera de guanyar-se la vida, sinó un deure i probablement un honor. Va haver un procés de professionalització del teatre i es van constituir companyies itinerants, $\tau \varepsilon \chi v i ̃ \tau \alpha$. Açò aniria produint una desvinculació de les representacions respecte a les ocasions tradicionals concretes amb què el teatre estava vinculat.

${ }^{10} \mathrm{El}$ mes de $\gamma \alpha \mu \eta \lambda \iota \omega ́ v$ correspondria més o menys al nostre gener o febrer.
} 
imitació a través d'una representació, és a dir, $\mu$ í $\gamma \sigma \iota \varsigma$, i que tenia una funció catàrtica que feia que el públic es purgara i purificarà (Aristòtil, Poètica 1447a i Aristòtil, Poètica 1449b).

Pel que fa a l'origen de la tragèdia, segons LESKY (1985: 256), Aristòtil atribuïa a Tespis la creació d'aquest gènere i aquesta teoria quedava recolzada pel fet que el marbre de Paros testificava junt amb la Suda que Tespis havia representat una tragèdia per primera vegada en l'Olimpíada cinquanta-una de les Grans Dionísies.

Els personatges d'aquest gènere solien ser herois mítics o reis que engrandien l'acció perquè estaven compromesos amb qualsevol projecte: aquests intentaven sempre arribar a algun tipus d'objectiu. L'acció superava l'esfera privada i així s'oferia una imatge de la magnífica noblesa de l'heroi, que el caracteritzava per ser l'hereter de l'èpica. El fet que el contingut de la tragèdia fora la llegenda heroica va suposar un element molt important per al desenvolupament $d$ 'aquest gènere perquè aquest tema es trobava en l'ànima de tota la població com a part de la seua història.

Un altre tret que caracteritza la tragèdia grega i constitueix una part fonamental de la seua estructura són els à $\gamma \tilde{\omega} v \varepsilon \varsigma$, característica fonamental de l'obra del nostre autor. Trobem a sovint personatges en conflicte amb un altre o en lluita contra les seues desgràcies o el destí que els espera.

Referent al cor, aquest exemplifica i amplifica l'acció; i de les obres que ens han arribat, la gran majoria són cors d'ancians i de dones, aquestes principalment eren les components del cor euripideu. El cor sofreix un procés de debilitament en la tragèdia, en els diàlegs entre els actors i el cor. Els primers van cobrant més importància paulatinament, però aquest procés es veu molt més remarcat a partir de la comèdia mitjana, en què el cor es va separant del contingut i de la representació dramàtica.

També cal mencionar la idea del destí que està present en la tragèdia, principalment en Sòfocles. Aquest és expressat molt sovint mitjançant els oracles que era el instrument pel qual els déus expressaven la seua voluntat als humans. Aquest destí no es pot transgredir, és inexorable, els herois de Sòfocles estan sols davant el seu destí, un destí que no comprenen i del que busquen l'explicació, però una vegada trobada la resposta del destí imposat, no poden fer més que acceptar-lo.

\section{EURÍPIDES}

Havent plantejat aquests aspectes introductoris sobre el teatre, és necessari analitzar alguns aspectes rellevants per a comprendre qualsevol obra, com són l'autor i el context històric del mateix.

En la tragèdia trobem tres tragediògrafs importants, Èsquil, Sòfocles i Eurípides, però nosaltres focalitzarem el treball en aquest últim, que és l'autor de l'obra que comentarem, encara que al llarg del treball compararem aquest amb els altres autors i les seues corresponents obres. 
Eurípides va nàixer l'any 485/484 aC a Salamina. ${ }^{11}$ Va passar pràcticament tota la seua vida retirat en aquesta ciutat, sense ser massa partícip de la política, però sí que estava al corrent dels moviments culturals i ideològics i de les doctrines filosòfiques d'Atenes. Va haver d'eixir d'Atenes en el $408 \mathrm{aC}$ per a anar a la cort del rei de Macedònia, Arquelau, que l'havia convidat, i allí va faltar entre el 407 i el 405 $\mathrm{aC}$ en Pel·la. ${ }^{12}$

Les tragèdies d'Eurípides deixen veure la diversitat de la seua personalitat poètica. És un poeta capaç d'un patetisme especialment persuasiu, afí a les noves modes musicals i als nous gustos intel-lectuals. Les noves corrents filosòfiques, principalment la sofística, arribaren a la política i al pensament i açò va influir molt en l'obra del nostre autor. Però l'expressió d'aquestes noves corrents i la crida a la reacció d'un canvi social no tingueren tan bona acollida en el públic. Les perspectives renovadores del nostre poeta tràgic no van triomfar tant en el seu moment com ho farien posteriorment, quan va ser reivindicat. En època hel·lenística ja constituïa una de les peces fonamentals en l'educació literària.

En les seues obres va intentar plasmar la crisi ideològica que estava succeint en el seu temps, una època on els valors tradicionals estaven en el punt de mira i eixes creences ancestrals es posaven en dubte. No obstant, en Eurípides coexisteixen diferents temàtiques i ideologies, per la qual cosa la seua obra s'ha interpretat de maneres oposades: racionalista/irracionalista, ateu/creient, misogin/defensor de les dones, etc. i és que l'autor reflexa totes aquestes oposicions. ${ }^{13}$

És innovador a l'hora de tractar el mite, principalment amb una idea clara: els deus que regeixen la vida humana estan subjectes a les passions que els mortals tracten de controlar. Amb freqüència segueix a Èsquil, però abandona d'alguna manera l'element sacre tradicional i afegeix un element més humà a les seues creacions. De la mateixa forma que el mite es dessacralitza, els personatges, els herois euripideus han perdut la seua grandesa mítica, la seua seguretat i en nombroses ocasions la seua proximitat als deus. Ja no són figures irrompibles i canvien de conducta molt a sovint, són més humans al cap i a la fi: caracteritzats amb debilitats psicològiques, dubtes ètics i comportaments banals, propers al ser humà corrent, dubten de la influència divina en la seua vida. Les trames de les seues obres són més complexes i no estan centrades en un sol personatge, no és la seua intenció mostrar la situació d'un protagonista sinó remarcar la totalitat del context social. En una línia similar dóna valor Eurípides a les accions de les dones, xiquets i altres personatges que fins aleshores no havien tingut tanta importància.

També és una tragèdia d'actualitat, d'intriga i d'idees, és més psicologista que les anteriors, se centra en els conflictes psicològics dels personatges, en els seus dilemes personals i reflecteix les seues

\footnotetext{
${ }^{11}$ Data fixada en el Marbre de Paros.

${ }^{12}$ Capital del regne de Macedònia.

${ }^{13}$ Cf. CAMPOS (2007), qui recull les diferents vessants de la figura polièdrica de l'autor.
} 


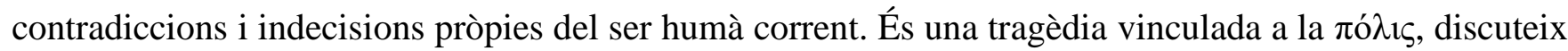
sobre la guerra, la política, els valors tradicionals imposats i els problemes contemporanis en general.

En Eurípides trobem una major presència de l'element femení. A diferència dels anteriors tragediògrafs, li dóna més importància a personatges que fins el moment no havien tingut tanta, com són les dones. També es mostra el tema de l'amor en diversos aspectes i el sofriment de la dona.

Eurípides va ser un autor molt criticat, com demostra Aristòfanes (no sabem fins a quin punt era crítica publicitària per a un amic), sobre tot per les seues noves idees i per el paper que adquireix la dona en les seues obres. Una gran font de crítiques està basada en l'actuació d'alguna de les seues heroïnes com ara la passional Medea, que mata als seus propis fills, l'Hècuba assassina dels fills del traïdor Poliméstor, o Fedra i el seu enamorament del seu fillastre a qui acusa de la seua pròpia passió. No obstant, després de la seua mort, la seua obra va ser representada de forma ininterrompuda i va anar guanyant el valor que es mereixia.

Quant al pròleg, l'autor l'utilitzava per a ajudar el públic a entendre millor l'obra explicant certs detalls rellevants o comentant quina versió del mite anava a seguir. ${ }^{14}$

En relació amb el cor, cal mencionar que les seues intervencions donaven una visió més completa i general de la trama. Malgrat que la crítica diga que Eurípides no integrava els cors com un personatge actiu com feien Sòfocles i Èsquil, la realitat és que hi ha cors molt actius en l'obra d'aquest autor, com el de Bacants i en general juguen un paper fonamental en el seu teatre per la seua qualitat poètica. La crítica fins els anys noranta va considerar que els seus cants corals eren com relats lírics completament independents, a causa de l'afirmació que va fer Aristòtil en Poètica 1456a, que va formar la base de les teories modernes sobre el paper tràgic del cor. No obstant, s'ha considerat després que els cants corals d'Eurípides no estan deslligats de l'acció i que a més donen una perspectiva més àmplia del context.

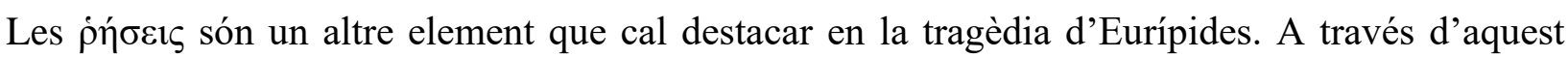
recurs, l'autor mostra les seues qualitats oratòries i retòriques, influenciat per la sofistica, i sol aparéixer

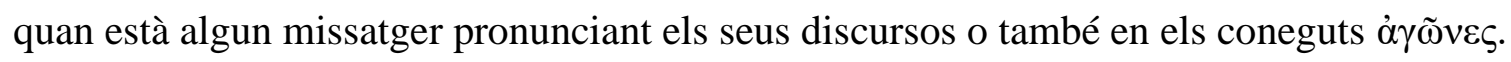

Un dels trets més importants d'aquest poeta tràgic és l'ús abundant d'à $\gamma \tilde{\omega} v \varepsilon \varsigma$, que apareixen al llarg de la seua producció literària conservada. Aquests estan emmarcats per un fort caràcter retòric que fa que s'intensifique el patetisme tràgic a causa de la influència que havia rebut l'autor de la retòrica del seu temps.

Una altra característica important en l'autor, i en la tragèdia en general, és l'aparició del deus ex machina. Se sol marcar una relació pel que fa a la temàtica entre el deus i el pròleg, perquè el que es comenta en el pròleg sovint es reafirma quan sorgeix el deus.

\footnotetext{
${ }^{14}$ Cf. BRASETE (2001) per a un estudi sobre l'ús del pròleg en Eurípides.
} 
La llengua amb què escriu l'autor és fonamentalment l'àtic, però també té en la part narrativa certes pinzellades del jònic i homerismes, i en la part lírica tocs de dòric literari. La seua llengua s'aproxima a la parla col·loquial, però això no vol dir que siga una llengua vulgar, sinó que posseeix senzillesa i claredat. Fa ús del $\alpha ð \pi \alpha \xi$, hipèrbatons i un lèxic més realista que l'apropa a la vida quotidiana. La llengua del teatre d'Eurípides és una combinació de grec àtic adornat amb jonismes i doricismes, però que comparada a la dels altres tràgics és més natural i clara.

Eurípides estava obert a tots els corrents intel-lectuals del seu temps, com per exemple a la sofística. L'autor reflecteix les idees noves dels sofistes que va veure arribar a la política i açò va fer que rebera crítiques de part dels seus contemporanis. L'autor també escriu obres polítiques, i d'una a l'altra pot canviar completament el seu pensament ideològic, per tant, no el podem emmarcar dins d'un posicionament ideològic en concret.

Un altre element que predomina en les seues obres és la retòrica. Eurípides va ser molt criticat i un dels motius era perquè els seus discursos eren massa retòrics. Consideraven que era més retòrica que tragèdia perquè aquesta dominava tota la trama i feia que els discursos pogueren resultar massa rígids.

En el cas de l'element retòric ens trobem amb certes contradiccions. D’una banda fa ús de la retòrica i ens explica que és un bon mitjà per a solucionar conflictes, en canvi en altres moments la critica. L'autor en nombroses ocasions fa parar l'acció de la trama per a regalar-nos discursos elaborats i extensos, però, en canvi altres vegades a través dels seus personatges fa una crítica a aquesta pràctica, a aquells que fan discursos massa llargs.

Com acabem de dir, Eurípides ens conta que la retòrica és una bona ferramenta per a resoldre qualsevol problema, però com bé ens explica LABIANO (2006: 32), "aunque se afirme una y otra vez que a través de la palabra todo puede arreglarse y lograrse, luego resulta que no hay prácticamente una sola situación en estas tragedias en las que se arregle un solo conflicto por medio de la palabra”. No obstant això, trobem alguna excepció, com en l'obra Helena, quan l'heroïna fa ús de l'art de la paraula i intenta persuadir Teònoe perquè no revele la identitat de Menelau al seu germà Teoclímen per a poder escapar i eixir vius d'Egipte (vv. 894-897). Finalment Teònoe acaba sent persuadida per Helena (v. 998 i vv. $1002-$ 1004).

De l'obra d'Eurípides ens han arribat dèsset tragèdies i un drama satíric, però la Suda (lèxic grec del s. X) ens informa que hauria compost uns noranta-dos drames, dels quals va obtindre cinc victòries. Nosaltres analitzarem la tragèdia Helena. 


\section{LA FIGURA D'HELENA I LA DONA EN LA TRAGÈDIA}

El gènere que ens ha arribat del teatre és tot d'homes i com que l'única veu que coneixem en el gènere és la masculina quan es parla sobre una dona en la tragèdia la percepció que es mostra sobre ella és la d'un home.

La idea que es tenia en general sobre la dona era d'indecent $\mathrm{i}$ immoral. Alguns deien que eren els antics aedes qui havien forjat aquesta concepció de la dona. No obstant això, la figura de la dona sobresortia cada vegada més en el teatre, hi havia més personatges femenins i es donava més importància a l'element femení.

En la tragèdia, l' $\hat{\eta} \theta$ os era «una caracterització preconcebuda a partir de la qual es genera un talant

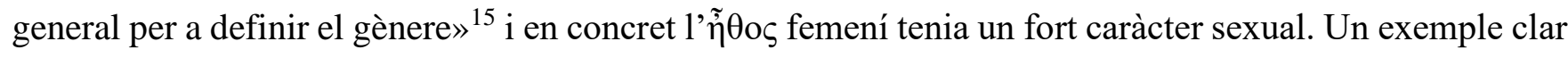
d'aquest element el tenim en Helena, que era concebuda com un objecte sexual, com una infidel. Segons la tradició oral, tots havien mantingut relacions sexuals amb ella, tant el seu marit Menelau, com el seu amant Paris, com tots els soldats aqueus que l'havien violada al véncer en la guerra de Troia, encara que aquesta visió de la història no succeeix en Helena d'Eurípides.

A part de ser concebuda com a objecte de sexualitat i violència, també era caracteritzada amb maldat. Es considerava que posseïa una bellesa tan gran com la maldat que tenia dins d'ella. Tota dona que gaudia del plaer era considerada immoral, com per exemple Helena o Clitemnestra, que eren considerades com l'ideal de dona terrible, mentre que la dona que actuava sempre en favor del seu home sacrificant-se era pura i bondadosa, com Alcestes o Andròmaca.

La dona sols havia de fer ús de la seua sexualitat en el matrimoni per tal de portar ciutadans al món. Aquesta sempre sofreix i mitjançant aquest $\pi \alpha ́ \theta$ os s'aconsegueix que el públic faça un exercici de catarsi. El patiment de la dona en el matrimoni l'explica molt bé Medea, que mostra el sofriment de l'esposa que no és lliure, que depén del seu marit i està sotmesa a aquest.

A més, qualsevol característica que fera a un home digne, en la dona era motiu de condemna. Un exemple podria ser el $\lambda$ ó $\gamma o \varsigma$, que sols estava reservat per a l'home; la dona estava mancada d'aquest i si alguna posseïa $\lambda$ ó $o \varsigma$ era malvada.

Com hem dit abans, la dona en la tragèdia és un personatge que en moltes ocasions pateix, les circumstàncies de la seua vida fan que estiga en una situació desgraciada, i aquest sofriment en Helena es reflecteix mitjançant les $\dot{\eta} \sigma \varepsilon ı \varsigma$. En aquestes la protagonista es remunta a un passat trist per tal de fer una enumeració de tots els mals que li han succeït; ens mostra una visió personal de les seues desgràcies.

Aquestes $\dot{\rho} \sigma \varepsilon ı \varsigma$ tenen una funció expressiva i referencial, estan constituïdes per narració i comentari personal, i mitjançant aquestes la protagonista expressa els seus sentiments sobre un passat ple

\footnotetext{
${ }^{15}$ Cf. GARCÍA (2011: 244).
} 
de mals i arriba a una conclusió a través d'una sèrie de reflexions: que part de la seua pena apunta directament al seu marit, Menelau, perquè Helena pensa que ha mort en la guerra, però que la seua màxima tristesa és que tota Grècia pense que ella és la culpable d'una guerra que ha deixat innumerables víctimes. Un exemple de $\rho \tilde{\sigma} \sigma i \varsigma$ el trobaríem en el primer diàleg entre Teucre i Helena, on el missatger informa l'heroïna d'allò ocorregut a Troia i a Grècia. Teucre podríem dir que té una funció referencial i la resposta d'Helena tindria més bé una funció fàtica i apel-lativa perquè li fa una sèrie de preguntes al missatger per tal de comprendre què ha passat exactament mostrant la seua desesperació davant la situació.

Sobre Helena tenim dos perspectives de la història completament oposades que resulten interessants. D’una banda, tenim la visió que ens proporciona la versió més tradicional del mite, on trobem una terrible esposa, infidel, que es deixa dur per les passions i abandona el seu marit Menelau escapantse amb l'amant, Paris, amb qui es casa quan arriba a Troia. És una Helena realment odiada pels dos bàndols perquè és la culpable d'una guerra i de la conseqüent mort de tots els soldats.

En canvi, la diferent perspectiva que ens ofereix Eurípides és que Helena no ha escapat en cap moment ni ha traït el seu marit, sinó que es troba a Egipte indefensa. Ací trobem una Helena, que encara que dins de la trama també és considerada pels grecs i pels troians com una mala dona, realment és una esposa fidel, que en cap moment vol unir-se a cap altre llit perquè no vol deshonrar Menelau. És una Helena que pateix i es preocupa pel seu marit i que fa tot el que està en les seues mans per salvar-lo i que seria capaç de sacrificar-ho tot per ell, inclús de llevar-se la vida si ell mor (vv. 795, 799, 835 i 839 ).

\section{HELENA D'EURÍPIDES}

El personatge d'Helena directa o indirectament apareix en les tragèdies el tema de les quals està relacionat amb la Guerra de Troia, que tantes desgràcies va causar als grecs i als troians. No obstant, no sempre ho fa en el mateix sentit: doncs unes vegades es fa a Helena responsable de la guerra $\mathrm{i}$ altres vegades se la disculpa. Per a entendre aquesta història ens hem de remuntar al judici de Paris, que és un dels episodis més coneguts del relat. Aquest conta que Eris, la deessa de la discòrdia, molesta per no haver sigut convidada a la boda de Peleu, es presenta en la cerimònia i deixa una poma dorada amb la frase "per a la més bonica". Tres de les deesses presents, Hera, Atenea i Afrodita es barallen per la poma, per la qual cosa, Zeus elegeix com a jutge al príncep pastor de Troia, Paris, per tal de dirimir la disputa. Les tres deesses intenten obtenir el seu favor oferint-li distints dons, però finalment elegeix a Afrodita, que li havia promés l'amor de la dona més bonica del món sencer. Esta dona és l'esposa del rei Menelau, Helena, que s'enamora de Paris, qui la rapta emportant-se-la a Troia, la qual cosa provoca la venjança de Menelau, que desencadena conseqüentment la guerra de Troia. ${ }^{16}$

\footnotetext{
${ }^{16}$ Ovidi, Heroides, Oenone Paridi vv. 33-74; Homer, Ilíada, XXIV, vv. 25-30.
} 
Eurípides és el tragediògraf que més al·lusions fa a aquesta heroïna i en dos de les seues obres conservades apareix com a personatge en escena. És el cas d'Orestes i Helena, on el tractament de l'esposa de Menelau canvia presentant-se baix una llum positiva o negativa, segons l'ocasió. Aquest canvi es deu a la diferent finalitat que l'autor persegueix amb la seua obra: la seua figura té una càrrega negativa quan vol atacar la tendència bel-licista del moment; en canvi, quan vol posar de relleu la inutilitat de la guerra, se serveix de la tradició, que estava present ja en Heròdot, per la que Helena mai ha estat en Troia, sinó que s'ha quedat refugiada en Egipte, fidel al seu marit.

La influència de la sofística en Eurípides juga un gran paper en la caracterització contradictòria i relativa que es fa d'un personatge que, a l'estar carregat d'una gran ambigüitat, s'establia com un objecte apropiat de discussió. No obstant, ja en els poemes homèrics apareix una versió del mite en què es podia incriminar a Helena o bé disculpar-la i fer responsables als deus. I en els textos literaris d'èpoques posteriors segueix ocorrent el mateix, doncs els fets que protagonitzava podien presentar-se de maneres distintes.

Hi ha pintures on es veuen les diferents representacions d'Helena a través de diferents trets físics: la noble i la bella "jove" d'Ilíada, la "senyora de la seua casa", que està casant a la seua filla en Odissea, la "engalanada, infidel i supèrbia", i la suplicant d'Helena. Estes diferents Helenes degueren ser impactants per als espectadors.

Helena d'Eurípides es va representar en l'any $412 \mathrm{aC}$ i constitueix una versió de la història d'Helena completament diferent a la que ens havia oferit fins el moment la tradició del mite, tant la trama com el personatge d'Helena són distints. Alguns estudiosos consideren que Helena és una de les obres d'Eurípides que s'aproxima al drama burgés, a la comèdia de Menandre, perquè està caracteritzada amb tocs novel·lescos, sentit d'humor i enginy. Aquesta versió ja l'havien comentada Estesícor i Heròdot, però Eurípides la remodela a la seua manera.

Tenim de rerefons una crítica als déus, que juguen amb les persones com marionetes per pura diversió i que encara que saben perfectament que Helena no està a Troia, sinó a Egipte, permeten que vagen a la guerra tantíssims soldats.

L'estructura de l'acció d'aquesta obra s'ha comparat amb la d'Ifigènia entre els taures, perquè ambdues obres presenten una parella que es troba en un país estranger, que rebutja els forasters, i han de tramar un pla per poder escapar. En les dues obres predomina el to novel-lesc i melodramàtic, i els embolics en tota la tensió dramàtica.

Helena és una obra caracteritzada per tres elements que són fonamentals per a l'acció de la trama,

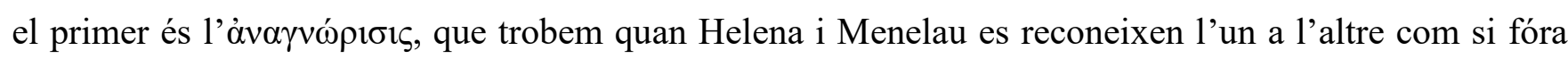
una espècie de final feliç; en segon lloc tenim el $\mu \eta \chi \alpha ́ v \eta \mu \alpha$, la intriga, que podem veure durant tota l'obra amb els diàlegs i les accions dels personatges que emmarquen l'acció, i finalment, els dei ex machina, que 
apareixen al final de l'obra fent una retrospecció de tot el que ha succeït i posant-li solució als problemes o les desgràcies que havien ocorregut.

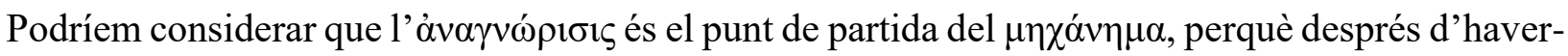
se reconegut els dos esposos és quan comencen a tramar una estratègia per a poder escapar, que és el punt on comença l'acció i la intriga.

La trama està plena d'obstacles i perills fins que té èxit el pla de fugida. Podem observar dues imatges paral·leles a l'encontre que podríem considerar com a obstacles; una és el primer diàleg entre Helena i el missatger Teucre i la segona imatge seria la de Menelau intentant parlar amb l'anciana del palau. Un altre obstacle seria el procés tan llarg en reconéixer-se l'un a l'altre que és molt característic en

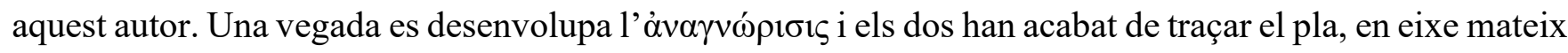
moment la intriga comença, i Menelau i Helena es dirigeixen ràpidament en busca de Teònoe per a posar en pràctica la seua tàctica.

La caracterització d'un personatge de vegades no es fa de forma explícita, sinó que apareix de manera indirecta a través dels seus actes, de l'estil a l'hora de parlar sol o amb altres personatges, del context en què es realitza l'acció, etc. Aquests elements en la tragèdia clàssica van vinculats directament

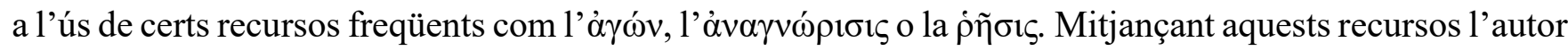
pot caracteritzar els seus personatges integrant-los directament en el conjunt de l'obra i aconseguint que aquests trets constituïsquen parts d'un tot. Podríem parlar aleshores de dos tipus de caracteritzacions del personatge: la ja mencionada exposició indirecta que estaria implícita en l'acció i una altra que seria verbalment explícita. No obstant, segons GómEZ (2015: 27-28), de vegades no és necessari que en cada manifestació verbal del personatge hi haja una revelació de la seua personalitat o idiosincràsia i inclús els trets del personatge poden entrar en contradicció amb els mencionats pel propi personatge o pels altres. Açò ens indueix per tant a plantejar-nos un anàlisi d'interpretació del text més exhaustiu encara. El personatge d'Helena en aquest cas es presenta principalment de manera implícita perquè els trets que li assignen els altres personatges no són els que realment li pertoquen a Helena sinó a l'eł̌ $\delta \omega \lambda o v$, la seua imatge fantasmagòrica. ${ }^{17}$

\section{ARGUMENT I CRÍTICA}

Primer ens agradaria recordar breument l'argument d'aquesta obra antibel·licista representada en el 412 aC: Helena, la causant de la guerra de Troia, no és més que un fantasma ideat pels deus, mentre que l'Helena real, mai havia anat a Troia i resideix en Egipte. És Proteu qui, per encàrrec d'Hermes, després d'haver-la raptat per voluntat d'Hera, la custodia i li dóna refugi. Mort aquest, el seu fill Teoclímen

\footnotetext{
${ }^{17}$ Cf. GóMEZ (2015: 29).
} 
intenta obligar-la a casar-se amb ell, però ella aleshores acudeix com a suplicant junt a la tomba de Proteu. Menelau, tornant de Troia amb el fantasma de la seua dona i errant des de feia set anys, se salva d'un naufragi. No obstant, en la trama ha de figurar com a mort per tal d'enganyar a Teoclímen i així poder salvar-se amb l'Helena real i tornar a Esparta, la seua ciutat. De fet, una vegada es reconeixen els esposos comença l'estratagema de l'engany: Helena li diu a Teoclímen que Menelau ha mort en la mar i ha d'oferir un sacrifici en honor al seu marit, i amb aquesta excusa, pugen a bord d'una nau, fugen, $\mathrm{i}$ arriben sans $\mathrm{i}$ estalvis a la seua pàtria.

En relació amb Helena, Heròdot ja diu que va marxar a Egipte, i Homer confirma aquest fet, fent que ella, en Odissea, oferisca a Telèmac la droga que fa oblidar les penes. Però açò no és el que precisament diu Eurípides. En efecte, Homer i Heròdot conten que ella, errabunda amb Menelau després del saqueig d'Ilió, arriba a Egipte; i que allí aconsegueix aquestes drogues que hem nomenat, mentre que Eurípides afirma que l'autèntica Helena no va anar en cap moment a Troia, sinó que va ser un fantasma seu. $^{18}$

La crítica moderna ha assignat a Helena d'Eurípides etiquetes tan diverses com "melodrama romàntic", "tragicomèdia" o "drama novel·lesc", etiquetes que són el resultat de no comprendre adequadament els components còmics i paròdics de la tragèdia i no exclusius del nostre tragediògraf. Principalment aquesta crítica es fa pel final feliç que pareix tenir: els dos esposos tornen sans i estalvis a la seua llar i allí "van viure feliços i van menjar anissos". Nosaltres considerem inqüestionable el fons seriós de l'obra, que es manifesta tant en les seues nombroses referències a la guerra i a la mort com en les reaccions i actituds dels personatges davant la particular situació dramàtica en què els ha col·locat Eurípides. Però, açò, poc a poc ho anirem desxifrant al llarg de la nostra anàlisi de l'obra.

Una breu ullada als tractaments dramàtics anteriors del personatge d'Helena ens ha fet veure que aquesta obra singular ens presenta una heroïna completament diferent a la visió general de la tradició del mite (no hi ha que oblidar, per exemple, la palinòdia d'Estesícor). Tots els trets que caracteritzen normalment Helena segons la tradició, Eurípides els inverteix. Aleshores, en lloc de veure la típica Helena infidel, egoista i malvada, que es deixa dur per les passions, ens trobem una heroïna innocent i fidel al seu marit, que es preocupa i se sacrifica pels altres.

Encara que Helena és un tragèdia, alguns estudiosos han vist en ella algunes parts còmiques. Per exemple, tenim el diàleg entre Menelau i l'anciana (vv. 437-482), en què els intents de dominació de Menelau acaben en completa derrota davant la dona major. A més, Eurípides juga amb la ignorància dels personatges que no comprenen l'antítesi entre aparença i realitat. D'aquesta manera posa en boca d'altres personatges comentaris irònics que els primers no entenen i que segurament provocarien la rialla de

\footnotetext{
${ }^{18}$ Cf. Herodot, Històries II, 118-119; Homer, Odissea, IV, vv. 227-230.
} 
l'espectador de l'època. És possible que resultara còmica, per exemple, la reacció del missatger quan veu Helena (vv. 616-621), precisament per no entendre aquesta dialèctica. Aquest tret ha creat controvèrsia sobre el gènere de l'obra, ja que alguns crítics moderns opinen que, pel final feliç i pels elements còmics que presenta, no ens trobem davant una tragèdia sinó d'un "melodrama romàntic", una "tragicomèdia" $o$ un "drama novel·lesc".

Quant a l'estructura d'aquesta tragèdia hem volgut destacar tres parts fonamentals: l'àvarvópıøıs, el $\mu \eta \chi \alpha ́ v \eta \mu \alpha$ i els dei ex machina. Totes les parts estan ben entrellaçades i cadascuna condueix a l'inici de la següent. L'escena de reconeixement entre els dos esposos els condueix al $\mu \eta \chi \alpha ́ v \eta \mu \alpha$, ja que han de tramar un pla per salvar-se i eixir de la situació de perill en què es troben. Al mateix temps, l'èxit de l'estratagema que fan servir, provoca una sèrie de conseqüències desfavorables que motiven l'aparició dels dei ex machina. Aquests últims sorgeixen per tal de resoldre tots els conflictes ocasionats i, a més, li anuncien a la seua germana que recuperarà allò que tant desitja, el seu honor (vv. 1662-1675). També hem volgut assenyalar una particularitat estructural que ens presenta l'autor en Helena. Al llarg de l'obra no ens trobem amb cap cant coral i al final d'aquesta tenim tres $\sigma \tau \alpha ́ \sigma u \alpha$ quasi seguits, que estan estretament relacionats amb els esdeveniments que està sofrint el matrimoni.

Un altre aspecte digne de menció és el paper crucial dels déus: al llarg de l'obra, molts esdeveniments estan regits per les divinitats. Un exemple n'és quan Teònoe informa els esposos que els déus celebraran una assemblea per decidir el destí dels dos (vv. 878-879). També hi podem veure una crítica implícita als designis capritxosos dels déus. Per exemple, el missatger comenta com d'imprevisibles són les divinitats (vv. 711-715), de la mateixa manera que ho fa el cor en el primer $\sigma \tau \alpha ́ \sigma u$ ov (vv. 1137-1150). Sembla que els déus sols es preocupen pels seus interessos personals i que no els importen les vides dels mortals (cosa ha fet que més d'un estudiós considere Eurípides dins de l'ateisme). Actuen en favor del seu propi benefici sense importar les conseqüències que tenen les seues accions en els éssers humans, com fan al crear l'eỉ $\delta \omega \lambda$ ov d'Helena per aconseguir els seus propòsits.

La dialèctica entre aparença i realitat és un dels temes principals i més recurrents que afecta a tots els personatges. Aquests no comprenen la relació entre aparença i realitat, cosa que els crea una gran confusió, producte de l'estratagema de les divinitats, com veiem en el cas de Menelau, Teucre i Teoclímen. Menelau, quan és informat per l'anciana, no entén com hi pot haver una Helena a Egipte (vv. 491-499).

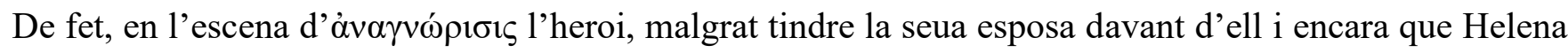
li explica tot el que ha succeït, continua sense comprendre-ho i no creu que siga realment ella (vv. 546596). No serà fins l'arribada d'un dels homes de Menelau, anunciant-li que l'Helena que estaven custodiant se n'ha anat volant, que l'heroi ho comprenga tot (vv. 622-624). Teucre, per la seua part, encara que és conscient que la dona que té al davant és físicament igual que Helena, no pot comprendre que siga ella (vv. 71-77, 80-82 i 158-163). Teoclímen també és víctima del mateix engany però aquest ho és a mans 
de la pròpia Helena. El missatger, company de Menelau, tampoc entén la dialèctica entre aparença i realitat quan veu l'heroïna (vv. 616-621).

Pel que fa al cor, hi ha una gran relació d'amistat entre les dones captives i Helena. Aquest grup d'esclaves, que es troben en una situació similar a la de l'heroïna, suposen un gran suport per a Helena al llarg de tota l'obra. El cor d'esclaves actuen com a confidents (vv. 179-190 i 211-228), conselleres (vv. 317-329) i aliades (vv. 1387-1389 i 1619-1620), de la mateixa manera que ho fa Teònoe quan ajuda el matrimoni a escapar (vv. 998-1012).

Un altre tema que cal destacar és la contraposició de personatges que s'estableix. L'autor ens presenta figures totalment contràries com Helena i Menelau, i com Proteu o Teònoe i Teoclímen. Aquests presenten caràcters oposats i tenen principis i valors contraris.

Els personatges a Helena no són estereotipats, sinó redons, és a dir, que pateixen transformacions líriques i dramàtiques al llarg de l'obra. El personatge d'Helena, per exemple, sofreix una gran evolució. Al principi de l'obra adopta una actitud passiva, de lamentació i es mostra sense capacitat de reaccionar i d'actuar. Però després pren les regnes de la situació, passa a controlar ella l'acció, trama el pla i s'encarrega de salvar el seu espòs i a ella mateixa. Finalment obté una recompensa pel seu esforç i els seus patiments, que és tornar a sa casa amb el seu marit, retrobar-se amb la seua filla i recuperar la bona reputació. Pel contrari, Menelau pateix una evolució a la inversa. Aquest, encara que al principi apareix amb una actitud derrotista i de lamentació, es presenta a si mateix com un home valerós, que ha sabut sobreviure i combatre nombroses adversitats. Menelau presenta un caràcter fort i dèspota, com podem veure en el diàleg amb l'anciana, però al final de l'obra adopta una actitud passiva i d'abatiment (vv. 1085-1089). Pel que fa al personatge de Teoclímen, podem apreciar que passa per diverses transformacions. A l'inici se'ns ofereix una imatge malvada d'ell, però quan apareix en persona sembla que és un poc ignorant i que no té massa autoritat. Al final de l'obra, quan se n'adona de l'engany d'Helena, entra en còlera (vv. 1624-1635), però finalment, quan intervenen els dei ex machina adopta una actitud de resignació i d'obediència i accepta tot el que li han transmés (vv. 1680-1682).

El sentiment de culpa de l'heroïna és un dels temes més rellevants de l'obra. Eurípides deixa patent la innocència d'Helena i, de fet, usa certs elements per remarcar-ho, com per exemple, el lligam que estableix entre Helena i Persèfone o les Nàiades (vv. 175 i 187). Helena és conscient que les divinitats han ocasionat les seues desgràcies i les responsabilitza en diverses ocasions de la seua mala fama, com fa amb Hera (vv. 260-261, 673-674), amb Cipris (vv. 680-683) i amb Zeus (vv. 36-41). No obstant això, té un profund sentiment de culpa per tot el que ha succeït. A més, tot el món pensa que Helena és la causant de totes les desgràcies que han ocorregut, fins i tot el seu propi marit (vv. 424-427 i 969-971). Aquest fet incrementa la sensació de culpabilitat, sentiment intensificat també per la seua bellesa. Helena és objecte 
de desig de tots els homes i els seus atributs són un dels causants de la seua mala reputació, cosa que també provoca en Helena un gran patiment (vv. 27, 363-364 i 383-385).

Hi ha una gran presència de patetisme en Helena. El sofriment d'Helena és manifest durant tota

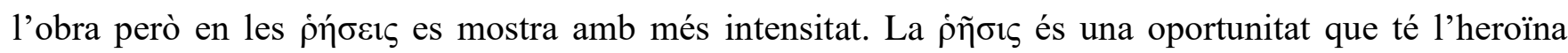
d'expressar els seus sentiments i de donar la seua opinió sobre les desgràcies que li han sobrevingut, com podem veure en els vv. 22-67 i 255-292. Aquest patetisme es fa més evident a l'inici de l'obra. Després de l'arribada de Teucre, Helena està sumida en una gran desesperació (vv. 191-210). Pensa que Menelau

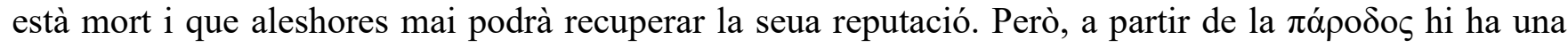
evolució progressiva que va des d'una tristesa profunda, passant per una actitud esperançadora, fins un acabament propici i positiu.

Pel que fa al desenllaç de l'obra cal destacar diversos elements que el preludien. Un d'aquests és quan Helena conta que Hermes va anunciar que tornaria a la seua pàtria amb Menelau (vv. 56-59). Un altre exemple el tenim quan, al final del primer diàleg entre Teucre i Helena, aquest li desitja el millor a l'heroïna i el pitjor a la seua imatge fantasmagòrica (vv. 162-163). I per últim, la menció a Persèfone per part d'Helena en el seu peà ens aboca a pensar en un possible retorn de l'heroïna a casa (v. 175).

Tot açò és el que hem anat veient en el nostre TFG, però som conscients que Helena també apareix en altres obres d'Eurípides. En el grup d'obres d'Eurípides en les quals Helena també participa com a personatge s'inclouen Troianes i Orestes. La representació de Troianes es creu que és tres anys anterior a la d'Helena, mentre que la d'Orestes és quatre anys posterior. ${ }^{19}$ En totes dues tragèdies el paper d'Helena és secundari, però les dues emmarquen l'obra Helena, que se situa cronològicament a mitjan camí entre aquestes i que posa en primer pla, quasi de principi a fi, les paraules i la presència física de l'esposa de Menelau. Eurípides situa Helena, tant en el pròleg de l'obra com al final d'aquesta, en un pla diferent al dels altres personatges.

En contemplar les accions i inaccions de l'heroïna, tant en aquestes últimes obres com en la tragèdia de la qual s'ocupa el nostre treball, un s'adona que el tractament dels personatges, de tots ells (fins i tot del cor) no és lineal i que depèn de l'objectiu principal que tinga el dramaturg per arribar com a "ensenyament" al públic.

\footnotetext{
${ }^{19}$ Tal com hem remarcat en la introducció del nostre treball, la cronologia exacta de l'obra euripidea és una qüestió que ha suscitat una gran controvèrsia entre els estudiosos.
} 


\section{BIBLIOGRAFIA}

\section{COMENTARIS, EDICIONS I TRADUCCIONS}

Allan, W. (2008). Euripides. Helen. Cambridge: Cambridge University Press.

Burian, P. (2007). Euripides. Helen. Oxford: Aris \& Phillips Classical Texts.

Dale, A. M. (1967). Euripides. Helen. Oxford: Clarendon Press.

Diggle, J. (1994). Euripidis Fabulae (Helena, Phoenissae, Orestes, Bacchae, Iphigenia Aulidensis, Rhesus), v. 3 Oxford: Clarendon Press.

FusILLO, M. (1997). Euripide. Elena. Milà: BUR.

KANNICHT, R. (1969). Euripides. Helena (II vols). Heidelberg: Winter.

Kovacs, D. (2002). Euripides: Helen, Phoenician Women, Orestes. Cambridge: Cambridge University Press.

LABIANO, J. M. (2000). Eurípides. Tragedias (III). Madrid: Cátedra.

Murray, G. (1909). Euripidis Fabulae, v. 3. Oxford: Clarendon Press.

RIU, X. (2017). Aristòtil. Poètica. Barcelona: Bernat Metge

\section{BIBLIOGRAFIA GENERAL}

Amoroso, F. (1978). "Solidarietà femminile e riscatto della donna dalla sua condizione in alcuni passi dell' Elena di Euripide", Pan 6: 47-51.

ARnotT, P. (1989). Public and Performance in the Greek Theatre. Londres i Nova York.

Badillo, P. (2002). El teatro griego: estudios sobre la tragedia, la comedia, Esquilo, Sófocles, Eurípides, Aristófanes, Menandro y la estructura dramática de las obras. Puerto Rico.

Barbanti, M. ET ALII (2002). Unione e amicizia. Omaggio a Francesco Romano. Catània.

BARRY, T. C. (1971). TO MESON: the function of the choral stasimon in Euripides' Helena. Yale.

BAÑUls, J. V. ET ALII (2007). O mito de Helena de Tróia à actualidade. Coímbra.

BlÁzQueZ, J. M. ET ALII (1989). Mosaicos romanos del Museo Arqueológico Nacional. Madrid.

Brasete, F. (2001). O Prologo na Tragedia Euripidiana. Tesi presentada en la Universitat d'Aveiro.

BuiJs, J. A. J. M. (1985). "Studies in the lyric metres of Greek tragedy", Mnemosyne ser. 4 38: 62-92.

CAIRns, D. (1993). Aidos. The Psychology and ethics of Honour and Shame in Ancient Greek Literature. Oxford. 
CAMPOS, J. ET ALII (2007). Las personas de Eurípides. Ámsterdam.

CAMPOS Daroca, F. J. (2013). "La sabiduría de Teónoe y los tiempos trágicos de la Helena de Eurípides". En F. De MARTino i C. MORENILla TALENS (eds.): 83-109.

Chong-Gossard, J.H. (2008). Gender and Communication in Euripides' Plays. Between Song and Silence. Leiden i Boston.

Clavo, M. I RIU, X. (2007). Teatre grec: perspectives contemporànies. Lleida.

CONACHER, D. J. (1967). Euripidean Drama: Myth, Theme and Structure. Toronto.

CONACHER, D. J. (2003). Euripides and the Sophists: Some Dramatic Treatments of Philosophical Ideas. Londres.

Cropp, M. J. FAntham, E. I SCUlly, S. E. (1986). Greek tragedy and its legacy: essays presented to D. J. Conacher. Calgary.

De Martino, F. i Morenilla, C. (2011). Teatro y sociedad en la Antigüedad clásica. La mirada de las mujeres. Bari.

De Martino, F. i Morenilla, C. (2013). Teatro y sociedad en la Antigüedad clásica. Palabras sabias de mujeres. Bari.

De Romilly, J. (1986). La modernité d'Euripide. París.

Di BENEDETTO, V. I MEDDA, E. (1997). La tragedia sulla scena. La tragedia greca in quanto spettacolo teatrale. Torí.

Dunn, F. M. (1996). Tragedy's End. Closure and Innovation in Euripidean Drama. Oxford i NovaYork. EASTERLING, P. (1987). "Women in Tragic Space”, BICS 34: 15-26.

FLETCHER, J. (2003). "Women and Oaths in Euripides", Theatre Journal 55: 29-44.

Foley, H. P. (2001). Female Acts in Greek Tragedy. Princeton i Oxford.

GARCíA, D. (2011). “Un argumento en la tragedia griega: ser mujer”. En F. DE MARTINO I C. MORENILLA (eds.): 239-257.

Gallé Cejudo, R. J. ET AliI (2016). Fronteras entre el verso y la prosa en la literatura helenística y helenístico-romana, Homenaje al Prof. José Guillermo Montes Cala. Bari.

GoldHILL, S. (1986). Reading Greek Tragedy. Cambridge.

GómEZ, F. (2015). Caracterización de Helena en la tragedia homónima de Eurípides. Tesi presentada en la Universitat de Santiago de Compostela.

Hose, M. (1990-1991). Studien zum Chor bei Euripides (II vols.). Stuttgart.

Hunter, V. (1990). "Gossip and the Politics of Reputation in Classical Athens", Phoenix 44: 299-325. JENS, W. (1971). Die Bauformen der griechischen Tragödie. Múnich. 
LABIANO, J. M. (2006). “Observaciones sobre Eurípides y su uso dramático de la Retórica”, Studia philologica valentina 9: 1-41.

LANZA, D. (2002). "La citta e i racconti. Riflessioni sullo statuto della poesia tra Platone e Aristotele". En M. BARBANTI, G. R. GiARdinA I P. MANGANARO (eds.): 77-88.

LESKY, A. (2001). La tragedia griega. Barcelona.

LESKY, A. (1985). Historia de la literatura griega. Madrid.

LLOYD, M. (1992). The agon in Euripides. Oxford.

LORAUX, N. (1989). Maneras trágicas de matar a una mujer. Madrid. Publicat per primera vegada en 1985. Façons tragiques de tuer une femme. París.

Marshall, C. W. (2014). The Structure and Performance of Euripides' Helen. Cambridge.

MASQueray, P. (1908). Euripide et ses idées. París.

MCCluRE, L. (1999). Spoken like a woman: speech and gender in Athenian Drama. Princeton.

MENDELSOHN, D. (2002). Gender and the city in Euripides' political plays. Oxford.

Michelini, A. N. (1987). Euripides and the Tragic Tradition. Madison.

Morenilla Talens, C. (2007). “La Helena de Eurípides”. En J. V. BAÑUls ET ALiI (eds.): 179-203.

Morenilla TAlens, C. (2013a). “Morir por espada, Helena, vv. 298-302”, Nova Tellus 31. 2: 43-64.

Morenilla TAlens, C. (2013b). "La Teónoe de Eurípides y la gnóme athánatos”, Euphrosyne 41: 321332.

Morenilla Talens, C. I BAÑUls, J. V. (2016). "El especial coro de la Helena de Eurípides". En R. J. GALLÉ CEJUDO ET ALII (eds.): 531-541.

Morenilla TAlens, C. I BAÑUls, J. V. (2012) "La Helena que nunca fue a Troya. De Estesícoro a Riaza", Fortunatae 23: 75-96.

Mossé, C. (1990). La mujer en la Grecia clásica. Madrid.

Murray, G. (1951). Euripides y su época. Ciutat de Mèxic. Publicat per primera vegada en 1913. Euripides and his age. Londres.

NÁPOLI, J. T. (1995). “El estásimo ditirámbico de la Helena de Eurípides”, Synthesis 2: 67-92.

NoRwoOD, G. (1948) [1920]. Greek Tragedy. Boston.

Pickard-Cambridge, A. (1927). Dithyramb, Tragedy and Comedy. Oxford.

PickARD-CAMBRIDGe, A. (1989). The Dramatic Festivals of Athens. Oxford. 
QuiJada SAgRedo, M. (1991). La composición de la tragedia tardía de Eurípides. Ifigenia entre los Tauros, Helena $y$ Orestes. Vitòria.

Rode, J. (1971). “Das Chorlied”. En W. JENS (ed.): 85-115.

RIU, X. (2007). “Teatre grec”. En M. Clavo I X. RIU (eds.): 131-151.

SCHADEwaldT, W. (1966). Monolog und Selbstgespräch. Berlín, Zúrich i Dublín.

SILK, M. S. (1996). Tragedy and the Tragic. Greek Theatre and Beyond. Oxford.

Taplin, O. (1977). The Stagecraft of Aeschylus: The Dramatic Use of Exits and Entrances in Greek tragedy. Londres.

VERnANT, J-P i VidAL-NAQUet, P. (1987). Mito y Tragedia en la Grecia antigua (II vols.). Madrid.

Verrall, A. W. (1905). Essays on Four Plays of Euripides. Andromache, Helen, Heracles, Orestes. Cambridge.

Winkler, J. I Zeitlin, N. (1990). Nothing to Do with Dionysos? Athenian Drama in Its Social Context. Princeton.

WinkLER, J. (1990). The constraints of Desire. The Anthropology of Sex and Gender in Ancient Greece. Nova York i Londres.

Wright, M. (2005). Euripides' Escape Tragedies: a study of Helen, Andromeda and Iphigenia among the Taurians. Oxford. 